\title{
Pengelompokan Data Kriminal Pada Poldasu Menentukan Pola Daerah Rawan Tindak Kriminal Menggunakan Data Mining Algoritma K-Means Clustering
}

\author{
Lilis Suriani \\ Program Studi Teknik Informatika, STMIK Budi Darma, Medan, Indonesia \\ Email: suryanililis016@gmail.com
}

\begin{abstract}
Abstrak-Kriminalitas merupakan segala macam bentuk tindakan dan perbuatan yang merugikan secara ekonomis dan psikologis yang melanggar hukum yang berlaku dalam negara Indonesia serta norma-norma sosial dan agama. Dapat diartikan bahwa, tindak kriminalitas adalah segala sesuatu perbuatan yang melanggar hukum dan melanggar norma-norma sosial, sehingga masyarakat menentangnya. Penelitian ini bertujuan untuk memudahkan dan membantu penegak hukum pihak poldasu untuk mengantisipasi tindak kriminal daerah rawan. Metode yang digunakan dalam penelitian ini adalah metode algoritma kmeans dengan menggunakan software rapidminer 7.3. Dimana dilakukan pengelompokkan untuk menentukan tingkat daerah rawan. Dengan dibuatnya sistem ini diharapkan dapat membantu pihak kepolisian dalam menentukan daerah rawan tindak kriminal. Dan dari hasil penelitian menyatakan kelompok daerah rawan tindak kriminal, yakni POLRESTA MEDAN dan POLRES LABUHAN BATU.
\end{abstract}

Kata Kunci: Kriminal, Data Mining, K-Means Clustering, Rapidminer

\begin{abstract}
Crime is all forms of actions and actions that are economically and psychologically harmful that violate the applicable laws in the Indonesian state and social and religious norms. Can be interpreted that, crime is anything that violates the law and violates social norms, so that the public opposes it. This study aims to facilitate and assist law enforcement authorities in anticipating criminal acts in vulnerable areas. The method used in this research is the k-means algorithm method using rapidminer 7.3 software. Where the grouping is done to determine the level of vulnerable areas. The establishment of this system is expected to assist the police in determining areas prone to crime. And from the results of the study stated groups of areas prone to criminal acts, namely MEDAN POLRESTA and LABUHAN BATU POLRES.
\end{abstract}

Keywords: Criminal, Data Mining, K-Means Clustering, Rapidminer

\section{PENDAHULUAN}

Tindak kriminalitas biasa berpengaruh terhadap keamanan masyarakat serta mengancam ketenangan lahir dan batinnya.Apabila masyarakat merasa terancam keamanannya maka besar kemungkinan pengaruhnya terhadap kesejahteraan dan ketentraman masyarakat tersebut. Kriminalitas merupakan segala macam bentuk tindakan dan perbuatan yang merugikan secara ekonomis dan psikologis yang melanggar hukum yang berlaku dalam Negara Indonesia serta norma-norma social dan agama.

Dalam hal ini Kepolisian Daerah Sumatera Utara tidak terlepas dari pengaduan-pengaduan masyarakat Sumatera Utara yang selalu berdatangan setiap hari. Dan data-data pengaduan tersebut akan di proses oleh pihak kepolisian sebagaimana yang telah di laporkan oleh para korban atau masyarakat. Laporan-laporan tersebut akan diinputkan kedalam sebuah basis data yang besar.oleh karena itu pada penelitian ini penulis menerapkan Data Mining untuk mengolah data kriminal yang bertujuan mengelompokkan data kriminal guna menentukan daerah rawan tindak kriminal pada daerah sumatra utara.

Data mining mampu menganalisa data yang besar menjadi informasi berupa pola yangmempunyai arti bagi pendukung keputusan. Namun banyaknya data yang ada ,tidak selalu dibarengi dengan pengetahuan yang dapat dihasilkan oleh data yang banyak tersebut, sehingga pada akhirnya data-data tersebut hanya menjadi suatu yang kurang berguna. Data mining merupakan proses pencaharian pola-pola yang menarik dan tersembunyi (hidden pattern) dari suatu kumpulan data yang berukuran besar yang tersimpan dalam suatu basis data ,seperti data were house dan tempat penyimpanan data lainnya[1].

Data mining disahkan dengan ekstraksi informasi yang diperlukan dari volume data yang besar seperti penelitian medis, manajemen hubungan pelanggan. Volume besar informasi individu dikumpulkan dan dianalisis dengan bantuan data mining. Tujuan melestarikan adalah untuk memodifikasi data asli menggunakan algoritma, sehingga data pribadi harus dilindungi[2].

Objek-objek/data yang dikelompokkan kedalam suatu grup memiliki ciri-ciri yang sama berdasarkan criteria tertentu, salah satu aktifitas analisis data adalah klasifikasi atau pengelompokkan data kedalam beberapa ketegori atau cluster. Untuk melakukan pengelompokan terhadap data pengelompokan suku cadang dana sesoris computer mengunakan teknik clustering.Metode yang digunakan K-Means Clustering.Dengan mengunakan metode ini data-data yang didapatkan dapat dikelompokkan kedalam beberapa cluster,berdasarkan kemiripan datadata tersebut, sehingga data-data yang dimilikikarakteristik yang sama dikelompokkan dalam satu cluster yang lain [1]. Salah satu metode yang digunakan dalam data mining adalah Clustering K-Means.Clustering K-Means merupakan salah satu algoritma data clustering non hirarki yang berusaha mempartisi data yang ada kedalam bentuk satu atau lebih cluster. 


\section{METODE PENELITIAN}

\subsection{Kriminal}

Kriminal merupakan segala macam bentuk tindakan dan perbuatan yang merugikan secara ekonomis dan psikologis yang melanggar hukum yang berlaku dalam negara Indonesia serta norma-norma sosial dan agama. Dapat diartikan bahwa, tindak kriminalitas adalah segala sesuatu perbuatan yang melanggar hukum dan melanggar norma-norma sosial, sehingga masyarakat menentangnya

\subsection{Konsep Dasar Data Mining}

Konsep dasar Data Mining digunakan untuk menemukan pola pola yang tersembunyi maupun hubunganhubungan yang terdapat dalam data base yang besar dan menghasilkan aturan-aturan yang digunakan[3].

\subsection{Clustering}

Pada dasarnya clustering merupakan suatu metode untuk mencari dan mengelompokkan data yang memiliki kemiripan karakteriktik (similarity) antara satu data dengan data yang lain. Clustering merupakan salah satu metode data mining yang bersifat tanpa arahan (unsupervised), maksudnya metode ini diterapkan tanpa adanya latihan (taining) dan tanpa ada guru (teacher) serta tidak memerlukan target output. Dalam data mining ada dua jenis metode clustering yang digunakan dalam pengelompokan data, yaitu hierarchical clustering dan nonhierarchical clustering [4].

\subsection{Proses Clustering}

Clustering merupakan salah satu teknik data mining yang digunakan untuk mendapatkan kelompok-kelompok dari obyek-obyek yang mempunyai karakteristik yang umum didata yang cukup besar. Tujuannya menemukan cluster yang berkualitas dalam waktu yang layak. Clustering dalam data mining berguna untuk menemukan pola distribusi di dalam sebuah data set yang berguna untuk proses analisa data. Kesamaan objek biasanya diperoleh dari kedekatan nilai-nilai atribut yang menjelaskan objek-objek data, sedangkan objek-objek data biasanya direpresentasikan sebagai sebuah titik dalam ruang multidimensi [4].

\subsection{Algoritma K-Means Clustering}

Algoritma K-Means Clustering adalah algoritma sederhana dan efektif untuk menemukan cluster dalam data dengan algoritma sebagai berikut [2]:

1. Tentukan k sebagai jumlah cluster yang ingin dibentuk. Tetapkan pusat cluster.

2. Hitung jarak setiap data ke pusat cluster menggunakan persamaan Euclidean.

$$
\mathrm{D}(\mathrm{ik})=\sqrt{\sum_{j}^{m}(C i j-C k j)^{2}}
$$

3. Kelompokkan data ke dalam cluster yang dengan jarak yang paling pendek menggunakan persamaan.

$$
\operatorname{Min} \sum_{k=1}^{k} d i k=\sqrt{\sum_{j}^{m}(C i j-C k j)^{2}}
$$

4. Hitung pusat cluster yang baru menggunakan persamaan

$$
\mathrm{C}_{\mathrm{kj}}=\frac{\sum_{i=1}^{p} X i j}{p}
$$

Dimana:

$\mathrm{X}_{\mathrm{ij}}$ E cluster $\mathrm{ke}-\mathrm{k}$.

\section{ANALISA DAN PEMBAHASAN}

Pada Kepolisian Daerah Sumatera Utara (POLDASU) terdapat 28 Polres dan semua data kriminal tiap-tiap Polres akan dijadikan sampel untuk penerapan Data Mining. Data-data tersebut tersedia dalam file Microsoft Excel yang telah diinput oleh penulis. Hal ini di karenakan pada proses pengujian, aplikasi rapidminer dapat mengolah file tipe .xls. Adapun data yang akan diolah pada penelitian ini dapat dilihat pada tabel 1 berikut:

Tabel 1. Data Kriminal Kepolisian Daerah Sumatera Utara (POLDASU)

\begin{tabular}{clcc}
\hline \multirow{2}{*}{ No } & \multicolumn{3}{c}{ Tahun 2017 } \\
\cline { 2 - 4 } & Satwil & JTP & TPTP \\
\hline 1 & Ditreskrimum & 973 & 703 \\
2 & Polresta Medan & 9423 & 6629 \\
3 & Polres Deli Serdang & 1507 & 859 \\
4 & Polres Tebing Tinggi & 824 & 505 \\
5 & Polres Sergai & 920 & 623 \\
6 & Polres Langkat & 1525 & 876
\end{tabular}




\begin{tabular}{clcc}
7 & Polres Binjai & 1181 & 709 \\
8 & Polres Tanah Karo & 860 & 402 \\
9 & Polres Simalungun & 1356 & 844 \\
10 & Polres P. Siantar & 608 & 330 \\
11 & Polres Asahan & 1865 & 1251 \\
12 & Polres Tjg. Balai & 380 & 159 \\
13 & Polres Labuhan Batu & 4256 & 2505 \\
14 & Polres Taput & 421 & 297 \\
15 & Polres Tobasa & 477 & 358 \\
16 & Polres Samosir & 171 & 103 \\
17 & Polres Humbahas & 308 & 202 \\
18 & Polres Dairi & 538 & 292 \\
19 & Polres Pakpak Bharat & 57 & 30 \\
20 & Polres Tapsel & 1426 & 777 \\
21 & Polres Padang Sidimpuan & 677 & 445 \\
22 & Polres Madina & 522 & 349 \\
23 & Polres Tapteng & 754 & 404 \\
24 & Polres Sibolga & 255 & 149 \\
25 & Polres Nias & 435 & 240 \\
26 & Polres Nias Selatan & 333 & 184 \\
27 & Polres Pelabuhan Belawan & 1409 & 977 \\
28 & Polres Batubara & 910 & 645 \\
\hline
\end{tabular}

Variabel yang digunakan pada penelitian ini adalah variable JTP dan TPTP dan selanjutnya akan dilakukan penentuan jumlah cluster dan titik pusat cluster awal yang dilakukan secara random.

Dari tabel tersebut, dapat diambil kesimpulan masing-masing titik awal Cluster berdasarkan urutan yang akan dilakukan penulis yakni daerah rawan tindak kriminal, sedang dan tidak rawan tindak kriminal adalah sebagai berikut:

1. Pusat Cluster I: Data ke-24 Polres Sibolga dengan JTP=255 dan TPTP $=149$

2. Pusat Cluster II: Data ke-7 Polres Binjai dengan JTP=1181 dan TPTP=709

3. Pusat Cluster III: Data ke-11 Polres Asahan dengan JTP=1865 dan TPTP=1251

a. Iterasi I

\begin{tabular}{|c|c|}
\hline Data-1 ke Pusat Cluster I & $\begin{array}{l}=\sqrt{(973-255)^{2}+(703-149)^{2}} \\
=\sqrt{515.524+306.916}=906,88\end{array}$ \\
\hline Data-2 ke Pusat Cluster I & $\begin{array}{l}=\sqrt{(9.423-255)^{2}+(6.629-149)^{2}} \\
=\sqrt{84.052 .224+41.990 .400}=11.226,8\end{array}$ \\
\hline Data-3 ke Pusat Cluster I & $\begin{array}{l}=\sqrt{(1.507-255)^{2}+(859-149)^{2}} \\
=\sqrt{1.567 .504+504.100}=1.439,30\end{array}$ \\
\hline Data-4 ke Pusat Cluster I & $\begin{array}{l}=\sqrt{(824-255)^{2}+(505-149)^{2}} \\
=\sqrt{323.761+126736}=671,19\end{array}$ \\
\hline Data-5 ke Pusat Cluster I & $\begin{array}{l}=\sqrt{(920-255)^{2}+(623-149)^{2}} \\
=\sqrt{442.225+224.676}=816,64\end{array}$ \\
\hline Data-6 ke Pusat Cluster I & $\begin{array}{l}=\sqrt{1.525-255)^{2}+(876-149)^{2}} \\
=\sqrt{1.612 .900+528.529}=1.463,36\end{array}$ \\
\hline Data-7 ke Pusat Cluster I & $\begin{array}{l}=\sqrt{(1.181-255)^{2}+(709-149)^{2}} \\
=\sqrt{515.524+306.916}=1.082,16\end{array}$ \\
\hline Data-8 ke Pusat Cluster I & $\begin{array}{l}=\sqrt{(860-255)^{2}+(402-149)^{2}} \\
=\sqrt{515.524+306.916}=655,77\end{array}$ \\
\hline Data-9 ke Pusat Cluster I & $\begin{array}{l}=\sqrt{(1.356-255)^{2}+(844-149)^{2}} \\
=\sqrt{515.524+306.916}=1.302,01\end{array}$ \\
\hline Data-10 ke Pusat Cluster I & $\begin{array}{l}=\sqrt{(608-255)^{2}+(330-149)^{2}} \\
=\sqrt{515.524+306.916}=396.70\end{array}$ \\
\hline Data-11 ke Pusat Cluster I & $\begin{array}{l}=\sqrt{(1.865-255)^{2}+(1.251-149)^{2}} \\
=\sqrt{515.524+306.916}=1.951,03\end{array}$ \\
\hline Data-12 ke Pusat Cluster I & $\begin{array}{l}=\sqrt{(380-255)^{2}+(159-149)^{2}} \\
=\sqrt{515.524+306.916}=125,40\end{array}$ \\
\hline
\end{tabular}




\begin{tabular}{|c|c|}
\hline Data-13 ke Pusat Cluster I & $\begin{array}{l}=\sqrt{(4.256-255)^{2}+(2.505-149)^{2}} \\
=\sqrt{515.524+306.916}=4.643,14\end{array}$ \\
\hline Data-14 ke Pusat Cluster I & $\begin{array}{l}=\sqrt{(421-255)^{2}+(297-149)^{2}} \\
=\sqrt{515.524+306.916}=222,40\end{array}$ \\
\hline Data-15 ke Pusat Cluster I & $\begin{array}{l}=\sqrt{(477-255)^{2}+(358-149)^{2}} \\
=\sqrt{515.524+306.916}=304,90\end{array}$ \\
\hline Data-16 ke Pusat Cluster I & $\begin{array}{l}=\sqrt{(171-255)^{2}+(103-149)^{2}} \\
=\sqrt{515.524+306.916}=95,77\end{array}$ \\
\hline Data-17 ke Pusat Cluster I & $\begin{array}{l}=\sqrt{(308-255)^{2}+(202-149)^{2}} \\
=\sqrt{515.524+306.916}=74,95\end{array}$ \\
\hline Data-18 ke Pusat Cluster I & $\begin{array}{l}=\sqrt{(538-255)^{2}+(292-149)^{2}} \\
=\sqrt{515.524+306.916}=317,08\end{array}$ \\
\hline Data-19 ke Pusat Cluster I & $\begin{array}{l}=\sqrt{(57-255)^{2}+(30-149)^{2}} \\
=\sqrt{515.524+306.916}=231,01\end{array}$ \\
\hline Data-20 ke Pusat Cluster I & $\begin{array}{l}=\sqrt{(1.426-255)^{2}+(777-149)^{2}} \\
=\sqrt{515.524+306.916}=1.328,77\end{array}$ \\
\hline Data-21 ke Pusat Cluster I & $\begin{array}{l}=\sqrt{(677-255)^{2}+(445-149)^{2}} \\
=\sqrt{515.524+306.916}=515,46\end{array}$ \\
\hline Data-22 ke Pusat Cluster I & $\begin{array}{l}=\sqrt{(522-255)^{2}+(349-149)^{2}} \\
=\sqrt{515.524+306.916}=333,60\end{array}$ \\
\hline Data-23 ke Pusat Cluster I & $\begin{array}{l}=\sqrt{(754-255)^{2}+(404-149)^{2}} \\
=\sqrt{515.524+306.916}=560,38\end{array}$ \\
\hline Data-24 ke Pusat Cluster I & $\begin{array}{l}=\sqrt{(255-255)^{2}+(149-149)^{2}} \\
=\sqrt{0}=0\end{array}$ \\
\hline Data-25 ke Pusat Cluster I & $\begin{array}{l}=\sqrt{(435-255)^{2}+(240-149)^{2}} \\
=\sqrt{515.524+306.916}=201,70\end{array}$ \\
\hline Data-26 ke Pusat Cluster I & $\begin{array}{l}=\sqrt{(333-255)^{2}+(184-149)^{2}} \\
=\sqrt{515.524+306.916}=85,49\end{array}$ \\
\hline Data-27 ke Pusat Cluster I & $\begin{array}{l}=\sqrt{(1.409-255)^{2}+(977-149)^{2}} \\
=\sqrt{515.524+306.916}=1420.32\end{array}$ \\
\hline Data-28 ke Pusat Cluster I & $\begin{array}{l}=\sqrt{(910-255)^{2}+(645-149)^{2}} \\
=\sqrt{515524+306916}=82161\end{array}$ \\
\hline
\end{tabular}

Hasil perhitungan menggunakan Euclidian Distance pada iterasi I tersebut diatas dapat dilihat pada tabel 2 berikut:

Tabel 2. Hasil Iterasi I

\begin{tabular}{|c|c|c|c|c|}
\hline \multirow{2}{*}{ Daka ke- } & \multirow{2}{*}{ Satwil } & \multicolumn{3}{|c|}{ Jarak Ke Centroid } \\
\hline & & $\mathrm{CO}$ & $\mathrm{C} 1$ & $\mathrm{C} 2$ \\
\hline 1 & Ditreskrimum & 906,88 & 208,09 & $1.046,88$ \\
\hline 2 & Polresta Medan & $11.226,87$ & $10.147,76$ & $9.276,11$ \\
\hline 3 & Polres Deli Serdang & $1.439,31$ & 358,85 & 530,87 \\
\hline 4 & Polres Tebing Tinggi & 671,19 & 411,18 & $1.280,70$ \\
\hline 5 & Polres Sergai & 816,64 & 274,80 & $1.134,64$ \\
\hline 6 & Polres Langkat & $1.463,36$ & 382,39 & 506,19 \\
\hline 7 & Polres Binjai & $1.082,16$ & 0 & 872,71 \\
\hline 8 & Polres Tanah Karo & 655,77 & 444,17 & $1.315,61$ \\
\hline 9 & Polres Simalungun & $1.302,01$ & 221,02 & 651,71 \\
\hline 10 & Polres P. Siantar & 396,70 & 687,00 & $1.558,30$ \\
\hline 11 & Polres Asahan & $1.951,03$ & 872,71 & 0 \\
\hline 12 & Polres Tjg. Balai & 125,40 & 971,65 & $1.843,28$ \\
\hline 13 & Polres Labuhan Batu & $4.643,14$ & $3.561,07$ & $2.699,89$ \\
\hline 14 & Polres Taput & 222,40 & 864,49 & $1.730,68$ \\
\hline 15 & Polres Tobasa & 304,90 & 786,65 & $1.650,45$ \\
\hline 16 & Polres Samosir & 95,77 & $1.177,85$ & $2.046,35$ \\
\hline 17 & Polres Humbahas & 74,95 & $1.009,54$ & $1.877,41$ \\
\hline
\end{tabular}




\begin{tabular}{llrrr}
18 & Polres Dairi & 317,08 & 766,38 & $1.637,26$ \\
19 & Polres Pakpak Bharat & 231.01 & 1313.17 & $2.181,67$ \\
20 & Polres Tapsel & $1.328,77$ & 254,26 & 646,06 \\
21 & Polres Padang Sidimpuan & 515,46 & 568,96 & $1.435,61$ \\
22 & Polres Madina & 333,60 & 750,92 & $1.617,79$ \\
23 & Polres Tapteng & 560,38 & 524,74 & $1.397,04$ \\
24 & Polres Sibolga & 0 & $1.082,16$ & $1.951,03$ \\
25 & Polres Nias & 201,70 & 881,18 & $1.751,29$ \\
26 & Polres Nias Selatan & 85,49 & 997,36 & $1.866,95$ \\
27 & Polres Pelabuhan Belawan & $1.420,32$ & 351,86 & 531,99 \\
28 & Polres Batubara & 821,61 & 278,45 & $1.131,04$ \\
\hline
\end{tabular}

Tahap selanjutnya adalah menentukan jarak terpendek data terhadap pusat cluster awal yang dipilih secara random sebelumnya. Menentukan jarak terpendek dengan pusat cluster data dapat menggunakan rumus MIN (Cij : Ckj : $\mathrm{Clj}$ ). Adapun hasil penentuan jarak terpendek terhadap pusat cluster yang telah ditabulasikan dapat dilihat pada tabel 3 berikut:

Tabel 3. Tabulasi Binner Jarak Terdekat Data terhadap Cluster

\begin{tabular}{|c|c|c|c|c|c|}
\hline \multirow{2}{*}{ Daka ke- } & \multirow{2}{*}{ Satwil } & \multicolumn{3}{|c|}{ Jarak Ke Centroid } & \multirow{2}{*}{ Cluster } \\
\hline & & $\mathrm{C} 0$ & $\mathrm{C} 1$ & $\mathrm{C} 2$ & \\
\hline 1 & Ditreskrimum & 0 & 1 & 0 & $\mathrm{C} 1$ \\
\hline 2 & Polresta Medan & 0 & 0 & 1 & $\mathrm{C} 2$ \\
\hline 3 & Polres Deli Serdang & 0 & 1 & 0 & $\mathrm{C} 1$ \\
\hline 4 & Polres Tebing Tinggi & 0 & 1 & 0 & $\mathrm{C} 1$ \\
\hline 5 & Polres Sergai & 0 & 1 & 0 & $\mathrm{C} 1$ \\
\hline 6 & Polres Langkat & 0 & 1 & 0 & $\mathrm{C} 1$ \\
\hline 7 & Polres Binjai & 0 & 1 & 0 & $\mathrm{C} 1$ \\
\hline 8 & Polres Tanah Karo & 0 & 1 & 0 & $\mathrm{C} 1$ \\
\hline 9 & Polres Simalungun & 0 & 1 & 0 & $\mathrm{C} 1$ \\
\hline 10 & Polres P. Siantar & 1 & 0 & 0 & $\mathrm{CO}$ \\
\hline 11 & Polres Asahan & 0 & 0 & 1 & $\mathrm{C} 2$ \\
\hline 12 & Polres Tjg. Balai & 1 & 0 & 0 & $\mathrm{CO}$ \\
\hline 13 & Polres Labuhan Batu & 0 & 0 & 1 & $\mathrm{C} 2$ \\
\hline 14 & Polres Taput & 1 & 0 & 0 & $\mathrm{CO}$ \\
\hline 15 & Polres Tobasa & 1 & 0 & 0 & $\mathrm{CO}$ \\
\hline 16 & Polres Samosir & 1 & 0 & 0 & $\mathrm{CO}$ \\
\hline 17 & Polres Humbahas & 1 & 0 & 0 & $\mathrm{CO}$ \\
\hline 18 & Polres Dairi & 1 & 0 & 0 & $\mathrm{CO}$ \\
\hline 19 & Polres Pakpak Bharat & 1 & 0 & 0 & $\mathrm{CO}$ \\
\hline 20 & Polres Tapsel & 0 & 1 & 0 & $\mathrm{C} 1$ \\
\hline 21 & Polres Padang Sidimpuan & 1 & 0 & 0 & $\mathrm{CO}$ \\
\hline 22 & Polres Madina & 1 & 0 & 0 & $\mathrm{CO}$ \\
\hline 23 & Polres Tapteng & 0 & 1 & 0 & $\mathrm{C} 1$ \\
\hline 24 & Polres Sibolga & 1 & 0 & 0 & $\mathrm{CO}$ \\
\hline 25 & Polres Nias & 1 & 0 & 0 & $\mathrm{CO}$ \\
\hline 26 & Polres Nias Selatan & 1 & 0 & 0 & $\mathrm{CO}$ \\
\hline 27 & Polres Pelabuhan Belawan & 0 & 1 & 0 & $\mathrm{C} 1$ \\
\hline 28 & Polres Batubara & 0 & 1 & 0 & $\mathrm{C} 1$ \\
\hline
\end{tabular}

Berdasarkan nilai minimum yang telah ditentukan menggunakan rumus dan hasil terlihat pada tabel 4 tersebut di atas, maka diperoleh hasil pengelompokan seperti terlihat pada tabel 5. berikut:

Tabel 4. Hasil Pengelompokan

\begin{tabular}{|c|c|c|}
\hline Kelompok (Cluster) & Anggota Cluster & Jumlah Anggota \\
\hline 0 & $\{10,12,14,15,16,17,18,19,21,22,24,25,26\}$ & 13 \\
\hline 1 & $\{1,3,4,5,6,7,8,9,20,23,27,28\}$ & 12 \\
\hline 2 & $\{2,11,13\}$ & 3 \\
\hline
\end{tabular}

Tahapan selanjutnya adalah menentukan titik pusat cluster baru yakni dengan mencari rata-rata semua anggota cluster dengan cara menjumlahkan seluruh value anggota cluster dibagi jumlah anggota. Adapun titik pusat cluster baru beserta value setiap variable adalah sebagai berikut: 


$$
\begin{aligned}
\mathrm{C}_{0}(\mathrm{X} 1)= & \frac{\text { Value JTP }(10,12,14,15,16,17,18,19,21,22,24,25,26)}{13} \\
& =\frac{(608+380+421+477+171+308+538+57+677+522+255+435+333)}{13} \\
& =\frac{5.182}{13}=398,62 \\
\mathrm{C}_{0}(\mathrm{X} 2)= & \frac{\text { Value TPTP }(10,12,14,15,16,17,18,19,21,22,24,25,26)}{13} \\
& =\frac{(330+159+297+358+103+202+292+30+445+349+149+240+184)}{13} \\
& =\frac{3.138}{13}=241,38 \quad 12 \\
\mathrm{C}_{1}(\mathrm{X} 1)= & \frac{\text { Value JTP }(1,3,4,5,6,7,8,9,20,23,27,28)}{12} \\
& =\frac{(973+1.507+824+920+1.525+1.181+860+1.356+1.426+754+1.409+910)}{12} \\
& =\frac{13.645}{12}=1.137,08 \\
\mathrm{C}_{1}(\mathrm{X} 2)= & \frac{\text { Value TPTP }(1,3,4,5,6,7,8,9,20,23,27,28)}{12} \\
& =\frac{(703+859+505+623+876+709+402+844+777+404+977+645)}{12} \\
& =\frac{8.324}{12}=693,67 \\
\mathrm{C}_{2}(\mathrm{X} 2) & =\frac{\text { Value JTP }(2,11,13)}{3} \\
& =\frac{(6.629+1.251+2.505)}{3} \\
\mathrm{C}_{2}(\mathrm{X} 1) & \frac{(9.423+1.865+4.256)}{3}=3.461,67 \\
& \frac{15.544}{3}=5.181,33 \\
&
\end{aligned}
$$

Berdasarkan proses perhitungan di atas, maka diperoleh centroid baru sebagai tolak ukur pada iterasi selanjutnya dengan nilai sebagai berikut:

$$
\begin{aligned}
& \mathrm{C}_{0}=[398,62 ; 241,38] \\
& \mathrm{C}_{1}=[1.137,08 ; 693,67] \\
& \mathrm{C}_{2}=[5.181,33 ; 3.461,67] .
\end{aligned}
$$

Adapun proses interasi sampai iterasi 2 s/d iterasi ke 4 seperti dibawah ini:

Tabel 5. Tabulasi Binner Iterasi 4

\begin{tabular}{clccc}
\hline \multirow{2}{*}{ No } & \multicolumn{1}{c}{ Satwil } & \multicolumn{3}{c}{ Jarak Ke Centroid } \\
\cline { 3 - 5 } & & $\mathrm{C} 1$ & $\mathrm{C} 2$ & $\mathrm{C} 3$ \\
\hline 1 & Ditreskrimum & 0 & 1 & 0 \\
2 & Polresta Medan & 0 & 0 & 1 \\
3 & Polres Deli Serdang & 0 & 1 & 0 \\
4 & Polres Tebing Tinggi & 1 & 0 & 0 \\
5 & Polres Sergai & 0 & 1 & 0 \\
6 & Polres Langkat & 0 & 1 & 0 \\
7 & Polres Binjai & 0 & 1 & 0 \\
8 & Polres Tanah Karo & 1 & 0 & 0 \\
9 & Polres Simalungun & 0 & 1 & 0 \\
10 & Polres P. Siantar & 1 & 0 & 0 \\
11 & Polres Asahan & 0 & 1 & 0 \\
12 & Polres Tjg. Balai & 1 & 0 & 0 \\
13 & Polres Labuhan Batu & 0 & 0 & 1 \\
14 & Polres Taput & 1 & 0 & 0 \\
15 & Polres Tobasa & 1 & 0 & 0 \\
16 & Polres Samosir & 1 & 0 & 0 \\
17 & Polres Humbahas & 1 & 0 & 0 \\
18 & Polres Dairi & 1 & 0 & 0 \\
19 & Polres Pakpak Bharat & 1 & 0 & 0 \\
20 & Polres Tapsel & 0 & 1 & 0 \\
21 & Polres Padang Sidimpuan & 1 & 0 & 0 \\
22 & Polres Madina & 1 & 0 & 0 \\
23 & Polres Tapteng & 1 & 0 & 0
\end{tabular}




\begin{tabular}{lllll}
24 & Polres Sibolga & 1 & 0 & 0 \\
25 & Polres Nias & 1 & 0 & 0 \\
26 & Polres Nias Selatan & 1 & 0 & 0 \\
27 & Polres Pelabuhan Belawan & 0 & 1 & 0 \\
28 & Polres Batubara & 0 & 1 & 0 \\
\hline
\end{tabular}

Hasil tersebut di atas dibandingkan dengan hasil iterasi ke-3 sebelumnya dan hasilnya adalah sama.Maka oleh karena itu, pencarian iterasi dihentikan dan hasil telah ditemukan. Dimana hasil dari pada pengelompokan dapat dilihat pada tabel 5, yaitu C3 adalah kelompok daerah rawan tindak kriminal, yakni POLRESTA MEDAN dan POLRES LABUHAN BATU.

\section{KESIMPULAN}

Dari hasil yang penulis lakukan terhadap penelitian ini penulis dapat menarik beberapa kesimpulan yang terkait dengan proses penelitian maupun dengan isi dari penelitian itu sendiri. Adapun kesimpulan - kesimpulan tersebut adalah sebagai berikut :

1. Pembagian pengelompokan daerah rawan Poldasu belum efektif dan efesien,dikerenakan belum adanya metode khusus untuk mendukung keberhasilan pembagian pengelompokkan daerah Rawan, dan masih dilakukan secara manual.

2. Melakukan pembagian kategori berdasarkan data-data JTP,JPTP,kemudian akan dikategorikan menjadi daerah rawan,sedang,tidak rawan,dengan nilai-nilai yang didapat pada setiap cluster..

\section{REFERENCES}

[1] R. I. Ndaumanu and M. R. Arief, Kusrini, “Analisis Prediksi Tingkat Pengunduran Diri Mahasiswa dengan Metode K-Nearest Neighbor," Jatisi, vol. 1, no. 1, pp. 1-15, 2014.

[2] F. Nasari and S. Darma, "Penerapan K-Means Clustering Pada Data Penerimaan Mahasiswa Baru," Semin. Nas. Teknol. Inf. dan Multimed. 2015, pp. 73-78, 2015.

[3] Sunjana, “Aplikasi Mining Data Mahasiswa dengan Metode Klasifikasi Decision Tree,” Seminar Nasional Aplikasi Tknologi Informasi. pp. $1-6,2010$

[4] K. Dumai et al., "IMPLEMENTASI ALGORITMA K-MEANS CLUSTERING UNTUK MENENTUKAN ARKETIPE PEMBELIAN SUKU CADANG DAN ASESORIS KOMPUTER ( STUDI KASUS DI TOKO LAKSAMANA Penelitian ini dilakukan untuk mempelajari Data Mining K-Means Clustering dalam pencarian knowledge ( pengetahu," vol. 9, no. 1, pp. 26-35, 2017.

[5] A. Jananto, "Penggunaan Market Basket Analysis untuk Menentukan Pola Kompetensi Mahasiswa," vol. 17, no. 2, pp. 82-89, 2012.

[6] T. Kristanto, R. Arief, D. Jurusan, and T. Informatika, “Analisa Data Mining Metode Fuzzy Untuk Customer Relationship Management Pada Perusahaan Tour \&," vol. d, no. 2009, pp. 2-4, 2013.

[7] K. Tampubolon, H. Saragih, B. Reza, K. Epicentrum, A. Asosiasi, and A. Apriori, "Implementasi Data Mining Algoritma Apriori Pada Sistem Persediaan Alat-Alat Kesehatan," Inf. dan Teknol. Ilm., pp. 93-106, 2013.

[8] D. Dwinavinta, C. Nugraha, M. Fahmi, Z. Naimah, and N. Setiani, "Klasterisasi Judul Buku dengan Menggunakan Metode K-Means," Semin. Nas. Apl. Teknol. Inf. Yogyakarta, vol. 21, no. 1, pp. 1907-5022, 2014

[9] A. Dahlan, E. Utami, and E. T. Luthfi, "Perancangan Data Warehouse Perpustakaan Perguruan Tinggi Xyz Menggunakan Metode Snowflake Schema," VIII NomorJurnal Teknol. Inf., vol. 24, no. November, pp. 1907-2430, 2013.

[10] J. O. Ong, "Implementasi Algotritma K-means clustering untuk menentukan strategi marketing president university," J. Ilm. Tek. Ind., vol. vol.12, no, no. juni, pp. 10-20, 2013. 